Article

\title{
Semi-Analytical Retrieval of the Diffuse Attenuation Coefficient in Large and Shallow Lakes from GOCI, a High Temporal-Resolution Satellite
}

\author{
Changchun Huang 1,2,3,4 (D) and Ling Yao $^{5, * \text { (D) }}$ \\ 1 School of Geography Science, Nanjing Normal University, Nanjing 210023, China; \\ huangchangchun@njnu.edu.cn \\ 2 State Key Laboratory of Lake Science and Environment, Nanjing Institute of Geography and Limnology, \\ Chinese Academy of Sciences, Nanjing 210023, China \\ 3 Key Laboratory of Virtual Geographic Environment (Nanjing Normal University), Ministry of Education, \\ Nanjing 210023, China \\ 4 Jiangsu Center for Collaborative Innovation in Geographical Information Resource Development and \\ Application, Nanjing Normal University, Nanjing 210023, China \\ 5 State Key Laboratory of Resources and Environmental Information System, Institute of Geographic Sciences \\ and Natural Resources Research, Chinese Academy of Sciences, Beijing 100101, China \\ * Correspondence: yaoling@lreis.ac.cn; Tel.: +86-10-6488-9045
}

Received: 20 May 2017; Accepted: 7 August 2017; Published: 11 August 2017

\begin{abstract}
Monitoring the dynamic characteristics of the diffuse attenuation coefficient $\left(K_{\mathrm{d}}(490)\right)$ on the basis of the high temporal-resolution satellite data is critical for regulating the ecological environment of lake. By measuring the in-situ $K_{\mathrm{d}}(490)$ and the remote-sensing reflectance, a semi-analytical algorithm for $K_{\mathrm{d}}(490)$ was developed to determine the short-term variation of $K_{\mathrm{d}}(490)$. From 2006 to 2014, the data about 412 samples (among which 60 were used as match-up points, 282 for calibrating dataset and the remaining 70 for validating dataset) were gathered from nine expeditions to calibrate and validate the aforesaid semi-analytical algorithm. The root mean square percentage error (RMSP) and the mean absolute relative error (MAPE) of validation datasets were respectively $27.44 \%$ and $22.60 \pm 15.57 \%$, while that of the match-up datasets were respectively $34.29 \%$ and $27.57 \pm 20.56 \%$. These percentages indicate that the semi-analytical algorithm and Geostationary Ocean Color Imager (GOCI) data are applicable to obtain the short-term variation of $K_{\mathrm{d}}(490)$ in the turbid shallow inland waters. The short-term GOCI-observed $K_{\mathrm{d}}(490)$ shows a significant seasonal and spatial variation and a similar distribution to the matching Moderate Resolution Imaging Spectroradiometer (MODIS) which derived $K_{\mathrm{d}}(490)$. A comparative analysis on wind (observed by buoys) and GOCI-derived $K_{\mathrm{d}}(490)$ suggests that wind is a primary driving factor of $K_{\mathrm{d}}(490)$ variation, but the lacustrine morphometry affects the wind force that is contributing to $K_{d}(490)$ variation.
\end{abstract}

Keywords: Geostationary Ocean Color Imager (GOCI); Lake Taihu; semi-analytical algorithm; wind speed

\section{Introduction}

The diffuse attenuation coefficient $\left(K_{\mathrm{d}}\right)$ is a fundamental optical property that describes the transfer process of light and heat in the aquatic ecosystems [1]. It is a better estimator of the euphotic depth and light availability in various depths compared with the traditional method using secchi disk. $K_{\mathrm{d}}$ is affected by the water constituents, the inherent optical properties, the incident light angle and etc., and thus obviously possesses the quasi-optical properties [2-4]. Therefore, the spatial and temporal variation of $K_{d}$ is significant since it could indicate the dynamic changes in these represented factors [5,6]. The accurate estimation of $K_{\mathrm{d}}$ and its distribution is critical for understanding 
and modeling the biochemical and physical processes, such as photobleaching, phytoplankton photosynthesis and organism mineralization in the euphotic zone of the aquatic ecosystems $[7,8]$.

Satellite remote sensing could promptly provide the repeated synoptic information on $K_{d}$ [9-11] and several empirical algorithms for $K_{d}$ at the wavelength of $490 \mathrm{~nm}\left(K_{d}(490)\right)$, which have been developed to estimate $K_{d}(490)$ in clear waters $[7,12,13]$. In order to accurately determine $K_{d}$ or $K_{\mathrm{d}}(490)$, Lee et al. [3] proposed a semi-analytical algorithm based on radiation transfer simulation. After that, Wang et al. [9] improved such semi-analytical algorithm because of its inability to predict backscatter coefficient $\left(b_{\mathrm{b}}\right)$ (estimation uncertainty $>50 \%$ ) in highly turbid coastal waters $[14,15]$. The improved semi-analytical algorithm could retrieve $K_{\mathrm{d}}$ and $K_{\mathrm{d}}(490)$ with a relatively acceptable accuracy in optically complex coastal waters $[9,11,15]$. Therefore, $K_{\mathrm{d}}$ and $K_{\mathrm{d}}(490)$ have become the important optical parameters for ocean satellite imagers, such as Moderate Resolution Imaging Spectroradiometer (MODIS), Sea-Viewing Wide Field-of-View Sensor (SeaWiFS), MEdium Resolution Imaging Spectrometer (MERIS) and Geostationary Ocean Color Imager (GOCI) [10,16-18], and are processed by the empirical or semi-analytical algorithms.

The empirical algorithms have also been used to estimate $K_{d}(490)$ and the diffuse attenuation coefficient of the photosynthetically active radiation $\left(K_{\mathrm{d}}(\mathrm{PAR})\right)$ in the extremely turbid and productive inland lakes $[5,7,17]$. However, the application of the semi-analytical algorithms for $K_{d}$ and $K_{d}(490)$ in the turbid inland lakes (such as Lake Taihu, the third largest freshwater lake in China) is seldom reported, which is primarily due to the following reasons: (1) in order to provide the accurate semi-analytical estimation of $K_{\mathrm{d}}$, the absorption $(a)$ and $b_{\mathrm{b}}$ must be derived precisely first [3]; (2) whether the quasi-analytical algorithm (QAA) [19] or $b_{\mathrm{b}}$ has been first derived or not $[9,20]$, the validated relationship between the remote-sensing reflectance $\left(R_{\mathrm{rs}}\right)$ and $a$ (or $\left.b_{\mathrm{b}}\right)$ is the foremost; and it's difficult to accurately measure the inherent optical properties, especially $b_{\mathrm{b}}$, in the highly turbid inland waters [21].

Based on satellite data, the long-term records of $K_{\mathrm{d}}$ in lakes have revealed the large temporal and spatial variation of $K_{d}$ caused by the meteorological and geographical features of lakes $[5,6,17]$. To reflect the significant short-term spatial and temporal variation of $K_{\mathrm{d}}$, a high temporal-resolution satellite is required to characterize the dynamic features of $K_{d}[10,11]$, which is particularly necessary for the shallow inland lakes having high dynamic ratio ((square root of the area)/depth), such as Lake Taihu with a dynamic ratio of 25.4. In conclusion, the semi-analytical algorithm of $K_{d}$ applied in GOCI satellite is important and critical to the observation of $K_{d}$ in the shallow inland lakes.

The objectives of this study were (1) to develop a semi-analytical algorithm of $K_{d}$ for the GOCI sensor based on $K_{\mathrm{d}}(490)$ and $R_{\mathrm{rs}}$ measured in situ, (2) to reveal the necessity of tracing the high temporal-resolution fluctuations in $K_{\mathrm{d}}(490)$, and (3) to monitor the highly dynamic characteristics of $K_{d}(490)$ by using GOCI-derived results.

\section{Materials and Methods}

\subsection{In-Situ Measurement}

\subsubsection{Study Area}

Located in the Yangtze River delta, Lake Taihu is a large shallow eutrophic lake with a surface area of $2338 \mathrm{~km}^{2}$ and a mean depth of $1.9 \mathrm{~m}$ [7]. In Lake Taihu, the sediment resuspension frequently occurs due to its high lacustrine dynamic ratio and the East Asian monsoon. Most water area of Lake Taihu is extremely turbid where $K_{\mathrm{d}}(490)$ can reach $20 \mathrm{~m}^{-1}$. However, East Lake and East Bay (see its aquatic plant in Figure 1) are very clear and contain a large amount of the submerged aquatic vegetation.

From 2006 to 2014, the remote-sensing reflectance $\left(R_{\mathrm{rs}}\right)$ and the ambient downwelling irradiance $\left(E_{\mathrm{d}}\right)$ were measured in situ by taking 473 samples in nine expeditions (respectively in November 2006, November 2007, November 2008, April 2009, May 2010, August 2011, October 2012, August 2013 and October 2014$)$. During the in-situ measurement of the optical properties $\left(R_{\mathrm{rs}}\right.$ and $\left.E_{\mathrm{d}}\right)$, water samples were collected. The water quality (suspended particulate matter, SPM) was measured in the laboratory 
within $24 \mathrm{~h}$ after water samples have been collected. In order to obtain the high-quality data about $K_{\mathrm{d}}(490)$, measurements carried out under the low solar radiance conditions $\left(E_{\mathrm{d}}(\lambda, \mathrm{z}) / E_{\mathrm{d}}\left(\lambda, 0^{+}\right)<1 \%\right)$ were removed. In final, we left 412 samples, among which 60 (from 6 August 2013 to 10 August 2013 marked in Figure 1) were used as match-up points (their in-situ measurement time is synchronous with the transit time of satellite images), and 282 were selected randomly to calibrate the model, while the remaining 70 were to validate the model. The wind speed and direction were observed by putting 10 buoys on the lake (see Figure 1 ).

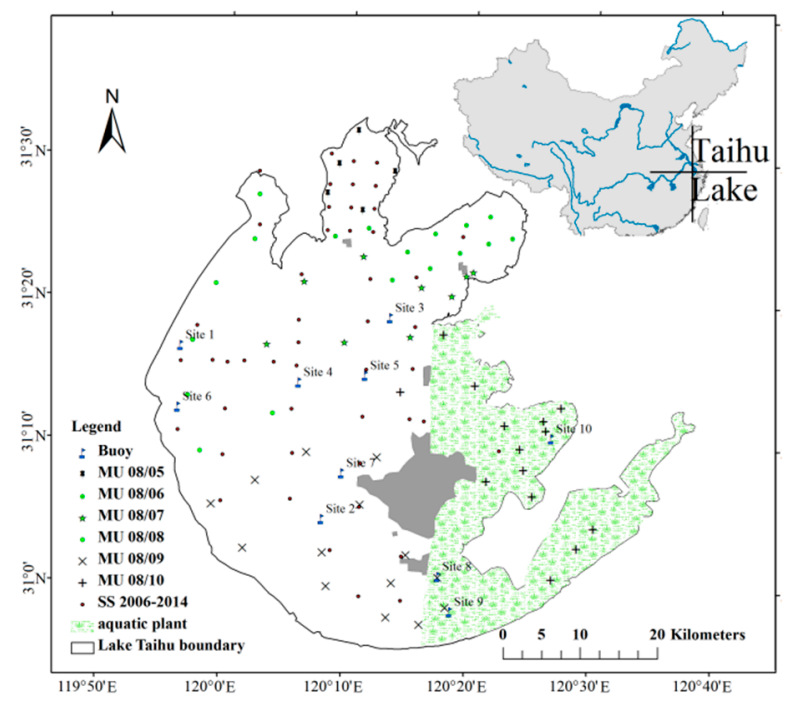

Figure 1. Sample sites of in-situ measurement. MU (match up points collected from 6 August 2013 to 10 August 2013) was marked from SS (sample sites) of the expeditions from 2006 to 2014.

\subsubsection{Measurements of the Optical Properties and SPM}

$R_{\text {rs }}$ (Figure 2A) was measured by using an analytical spectral device, i.e., the FieldSpec spectroradiometer (350-1050 nm with the sampling interval of $1 \mathrm{~nm}$ ). Each element (reference panel, water and sky) was measured after instrument optimization and calibrating for dark current. The radiances of reference panel $\left(L_{\mathrm{p}}\left(\lambda, 0^{+}\right)\right)$, water $\left(L_{\mathrm{sw}}\left(\lambda, 0^{+}\right)\right)$, sky $\left(L_{\mathrm{sky}}\left(\lambda, 0^{+}\right)\right)$and the panel again were measured ten times with the abnormal spectra being removed [22]. The rest of spectra were used to calculate $R_{\mathrm{rs}}$ according to the following formula:

$$
R_{\mathrm{rs}}(\lambda)=\left(L_{\mathrm{sw}}\left(\lambda, 0^{+}\right)-\mathrm{r} * L_{\mathrm{sky}}\left(\lambda, 0^{+}\right)\right) /\left(L_{\mathrm{p}}\left(\lambda, 0^{+}\right) * \pi / \rho_{\mathrm{p}}(\lambda)\right)
$$

where $r$ refers to the air-water surface reflectance (with a value of $2.45 \%$ ), and $\rho_{p}(\lambda)$ refers to the reflectance of the standard reflectance panel.

Downwelling irradiance $\left(E_{\mathrm{d}}(\lambda, z)\right)$ was measured by TriOS RAMSES-ARC (Ramses, Germany) with a spectral resolution of $3.3 \mathrm{~nm}$ (sampling interval of $1 \mathrm{~nm}$ ) for each depth (from 0.2 to $1.4 \mathrm{~m}$ with the interval of $0.2 \mathrm{~m}$ ). Each depth was measured for ten times with the abnormal spectra being removed, by using a method which is similar to the estimation process of $R_{\mathrm{rs}} . K_{\mathrm{d}}$ (see Figure $2 \mathrm{~B}$ ) using a non-linear fit between $E_{\mathrm{d}}(\lambda, z)$ and depth $(z)$ :

$$
E_{\mathrm{d}}(\lambda, z)=E_{\mathrm{d}}\left(\lambda, 0^{-}\right) \times \exp \left(-K_{\mathrm{d}}(\lambda) \times z\right)
$$

$K_{\mathrm{d}}$ is acceptable when $R^{2}$ of non-linear fit regressions $\geq 0.99$ and the number of depths in regressions $\geq 4$. 

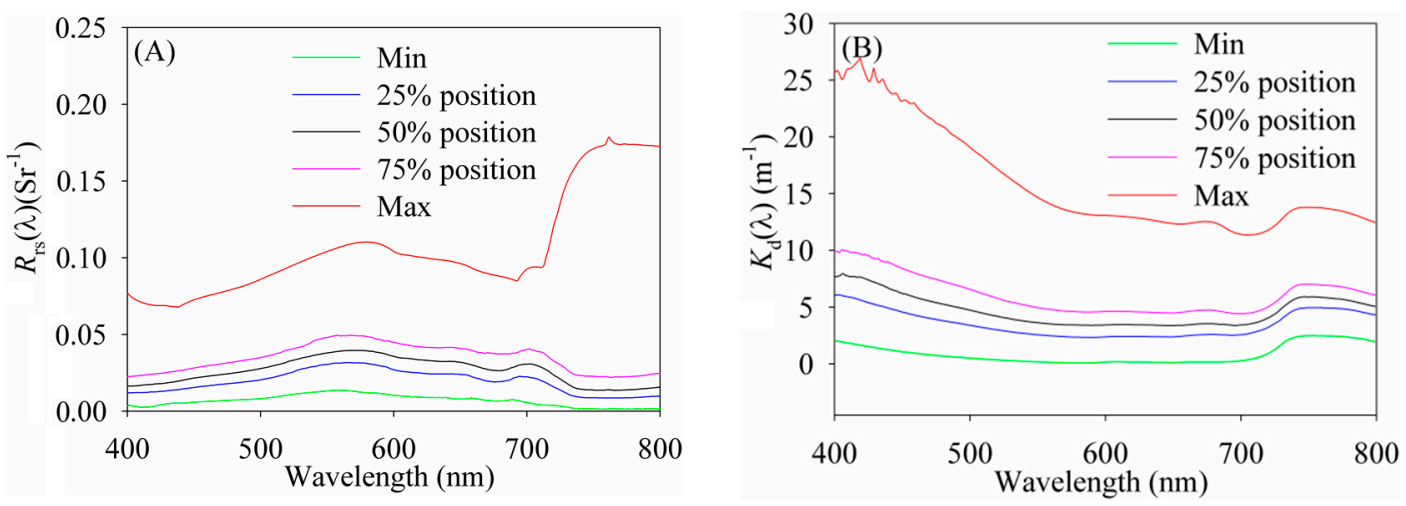

Figure 2. In-situ measurement of the remote-sensing reflectance (A) and the diffuse attenuation coefficient (B). The $25 \%, 50 \%$ and $75 \%$ lines respectively indicated the quarter, median and three-quarter levels of $R_{\mathrm{rs}}$ and $K_{\mathrm{d}}$ datasets, and Min and Max respectively refer to the minimum and maximum values of datasets.

SPM was obtained by measuring the mass differences between the pre-combusted ( $550{ }^{\circ} \mathrm{C}$ for $4 \mathrm{~h}$ ) and dried $\left(105^{\circ} \mathrm{C}\right.$ for $\left.4 \mathrm{~h}\right) 07-\mu \mathrm{m}$ Whatman GF/F glass fiber filters both before and after filtration of whole water field samples.

\subsection{Satellite Data and Preprocessing}

GOCI is the first geostationary ocean-color satellite sensor, with the spatial resolution of $500 \mathrm{~m}$ and the temporal resolution for one hour (eight times per day, i.e., from local time 8:30 to 15:30). The matching GOCI images (level-1b, from 8 June 2013 to 8 September 2013) were downloaded from Korea Ocean Satellite Center (http:/ / kosc.kiost.ac/eng/). The data and processes of geometry and atmosphere corrections were the same as the study of Huang et al. [23].

MODIS images from 8 June 2013 to 8 September 2013 were downloaded from the US NASA Goddard Space Flight Center (GSFC, http: / / oceancolor.gsfc.nasa.gov). The radiometric and geometric correction of the acquired MODIS Aqua Level 0 data was processed by SeaDAS 6.4. The parameters (satellite angle information, ozone and water vapor) from SeaDAS 6.4 were used as the input parameters in the atmospheric correction. The land target-based atmospheric correction method [24,25] was selected to derive reflectance from the MODIS-Aqua data over Lake Taihu.

\subsection{Accuracy Assessment}

The root mean square percentage error (RMSP) and the mean absolute relative error (MAPE) were used to assess accuracy of the model performance:

$$
\begin{gathered}
\text { MAPE }=\sum\left|\frac{K_{\text {estimated }}-K_{\text {measured }}}{K_{\text {measured }}}\right| / N \times 100 \% \\
\text { RMSP }=\sqrt{\sum_{\mathrm{i}=1}^{\mathrm{n}}\left(\frac{K_{\text {estimated }}-K_{\text {measured }}}{K_{\text {measured }}}\right)^{2} / N} \times 100 \%
\end{gathered}
$$

\section{Model $K_{\mathrm{d}}(490)$}

\subsection{Calibration}

The relationship between $K_{\mathrm{d}}$ and the inherent optical properties ( $a$ and $b_{\mathrm{b}}$ ) was used by Lee et al., to estimate $K_{d}$ semi-analytically [3]:

$$
K_{\mathrm{d}}\left(\lambda_{0}\right)=m_{0} a\left(\lambda_{0}\right)+m_{1}\left(1-m_{2} \exp \left(-m_{3} a\left(\lambda_{0}\right)\right)\right) b_{\mathrm{b}}\left(\lambda_{0}\right)
$$


The four model parameters $\left(m_{0}, m_{1}, m_{2}\right.$ and $\left.m_{3}\right)$ were estimated by curve fitting from the simulated data of radiation transfer (values of $m_{0}, m_{1}, m_{2}$ and $m_{3}$ are listed in [3]). At first, in order for the accurate estimation of $K_{\mathrm{d}}\left(\lambda_{0}\right)$, the inherent optical properties $\left(a\left(\lambda_{0}\right)\right.$ and $\left.b_{\mathrm{b}}\left(\lambda_{0}\right)\right)$ should be derived precisely by Equation (4a). According to Doron et al. [20] and Wang et al. [9], an empirical relationship between $b_{\mathrm{b}}\left(\lambda_{0}\right)$ and $R_{\mathrm{rs}}$ based on red wavelength in turbid water (Equation (4b)) was established. However, due to the uncertainty in measurement of $b_{\mathrm{b}}$ in the highly turbid inland waters [21], the model parameters $\left(A_{0}\right.$ and $\left.A_{1}\right)$ are hard to estimate via the in-situ measurement of $b_{\mathrm{b}}\left(\lambda_{0}\right)$ and $R_{\mathrm{rs}}$. Thus, this relationship was used to model $K_{\mathrm{d}}\left(\lambda_{0}\right)$ combined with Equation (4a-e).

$$
\begin{gathered}
\ln \left(b_{\mathrm{bp}}\left(\lambda_{0}\right)\right)=A_{0} \times \ln \left(\frac{R_{\mathrm{rs}}\left(\lambda_{i}\right)}{R_{\mathrm{rs}}\left(\lambda_{j}\right)}\right)+A_{1} \\
a\left(\lambda_{0}\right)=\frac{\left(1-U\left(\lambda_{0}\right)\right)}{U\left(\lambda_{0}\right)} b_{\mathrm{b}}\left(\lambda_{0}\right) \\
U\left(\lambda_{0}\right)=\frac{b_{\mathrm{b}}\left(\lambda_{0}\right)}{a\left(\lambda_{0}\right)+b_{\mathrm{b}}\left(\lambda_{0}\right)}=\frac{-0.084+\left(0.084+4 \times 0.17 \times r_{\mathrm{rs}}\left(\lambda_{0}\right)\right)^{1 / 2}}{2 \times 0.17} \\
R_{\mathrm{rs}}\left(\lambda_{0}\right)=0.52 r_{\mathrm{rs}}\left(\lambda_{0}\right) /\left(1-1.7 r_{\mathrm{rs}}\left(\lambda_{0}\right)\right)
\end{gathered}
$$

where $r_{\text {rs }}(\lambda)$ refers to the remote-sensing reflectance just beneath the water surface and $U(\lambda)$ refers to the intermediate variable. The modeled $K_{\mathrm{d}}\left(\lambda_{0}\right)$ (noted as $K_{\mathrm{d}}\left(\lambda_{0}\right)_{\text {modeled }}$ ) and the in-situ measured $K_{\mathrm{d}}\left(\lambda_{0}\right)$ (noted as $K_{\mathrm{d}}\left(\lambda_{0}\right)_{\text {measured }}$ ) were used to estimate $A_{0}$ and $A_{1}$ via the optimal computation according to the following objective equation:

$$
F_{\text {obj }}=-\sqrt{\sum_{\mathrm{i}=1}^{n}\left(K_{\mathrm{d}}\left(\lambda_{0}\right)_{\text {measured }}-K_{\mathrm{d}}\left(\lambda_{0}\right)_{\text {modeled }}\right)^{2} / n}
$$

Finally, the model parameters $\left(A_{0}\right.$ and $\left.A_{1}\right)$ and the optimal bands $\left(\lambda_{j}\right.$ and $\lambda_{j}$ in Equation (2)) were obtained when $F_{\text {obj }}$ met the minimum value.

Three bands $\left(\lambda_{0}, \lambda_{i}\right.$ and $\left.\lambda_{j}\right)$ are necessary in this semi-analytical model. However, due to the ambiguous extrapolation index of the aerosol model $[6,9,26]$, it's very difficult to accurately estimate $R_{\mathrm{rs}}$ from satellite images at short wavelengths (such as $\left.R_{\mathrm{rs}}(490)\right)$ in the highly turbid inland water. There are two methods which can be used to deal with such problem. One is to calculate $R_{\mathrm{rs}}(490)$ by taking use of the satellite-derived $R_{\mathrm{rs}}\left(\lambda_{0}\right)$ and its in-situ relationship with $R_{\mathrm{rs}}(490)$. The other is to firstly estimate $K_{\mathrm{d}}\left(\lambda_{0}\right)$ when $R_{\mathrm{rs}}\left(\lambda_{0}\right)$ can be derived well, and then calculate $K_{\mathrm{d}}(490)$ by taking use of the in-situ relationship between $K_{d}(490)$ and $K_{d}\left(\lambda_{0}\right)$. The comparison of relationship between $K_{d}(\lambda)$ and $R_{\mathrm{rs}}(\lambda)$ suggests that the relationship between $K_{\mathrm{d}}(490)$ and $K_{\mathrm{d}}\left(\lambda_{0}\right)$ (see Figure $3 \mathrm{~A}$ ) is much stronger than the relationship between $R_{\mathrm{rs}}(490)$ and $R_{\mathrm{rs}}\left(\lambda_{0}\right)$ (see Figure $3 \mathrm{~B}$ ). Thus, we chose to estimate $K_{\mathrm{d}}(490)$ by retrieving $K_{\mathrm{d}}\left(\lambda_{0}\right)$.

The calibration dataset, with $K_{\mathrm{d}}(490)$ ranging from 1.82 to $19.45 \mathrm{~m}^{-1}$, was used to calibrate the semi-analytical model of $K_{\mathrm{d}}(490)$. The optimal band ratio in Equation (4b) was confirmed as $R_{\mathrm{rs}}(660) / R_{\mathrm{rs}}(555)$ via the iterative computation of $R_{\mathrm{rs}}\left(\lambda_{i}\right)$ and $R_{\mathrm{rs}}\left(\lambda_{j}\right)$ within the range of the GOCI band $\left(\lambda_{0}\right.$ was set as $\left.660 \mathrm{~nm}\right)$. Consequently, two bands $\left(R_{\mathrm{rs}}(660), R_{\mathrm{rs}}(660) / R_{\mathrm{rs}}(555)\right)$ were used to estimate $K_{\mathrm{d}}(660)$ from which $K_{\mathrm{d}}(490)$ can be calculated. The optimal model parameters of $A_{0}$ and $A_{1}$ are 2.7714 and 0.8134 , respectively. The RMSP and MAPE between $K_{\mathrm{d}}(490)_{\text {modeled }}$ and $K_{\mathrm{d}}(490)_{\text {measured }}$ are respectively $24.80 \%$ and $19.38 \pm 14.47 \%$ (Figure $4 \mathrm{~A}$ ). The intermediate variable and backscatter coefficient at $660 \mathrm{~nm}, b_{\mathrm{bp}}(660)$, are highly positively correlated to the suspended particulate matter $\left(b_{\mathrm{bp}}(660)=0.4068^{*} \mathrm{SPM}^{0.3409}, R^{2}=0.71\right)$ (Figure $\left.4 \mathrm{~B}\right)$. The parameters of $K_{\mathrm{d}}(490)$ algorithm for MODIS were confirmed by using a method similar to the one used for GOCI [27]. 

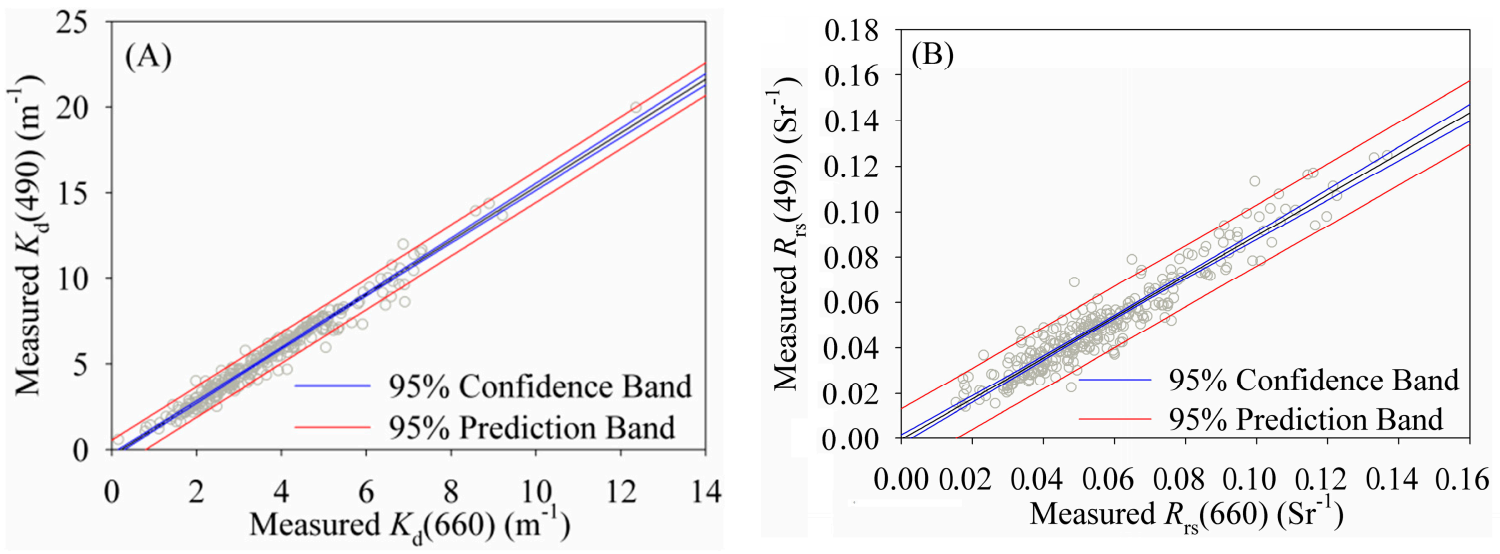

Figure 3. The in-situ relationships between $K_{\mathrm{d}}(490)$ and $K_{\mathrm{d}}(660)(\mathbf{A})$, and between $R_{\mathrm{rs}}(490)$ and $R_{\mathrm{rs}}(660)$ (B). The relationships are $K_{\mathrm{d}}(490)=1.5706^{*} K_{\mathrm{d}}(660)-0.3535, R^{2}=0.97$ and $R_{\mathrm{rs}}(490)=0.8989 * R_{\mathrm{rs}}(660)-$ $0.0004, R^{2}=0.90$.
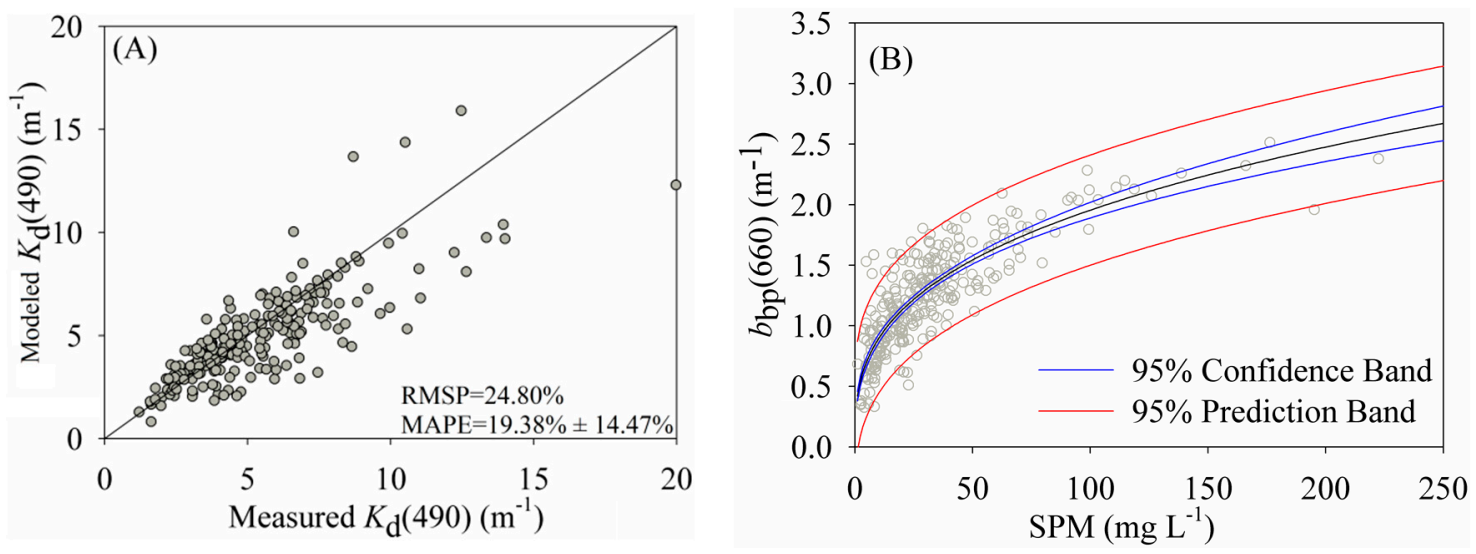

Figure 4. (A) Comparison of the in-situ measured $K_{d}(490)$ and the modeled $K_{d}(490)$ by using retrieval algorithm in this study. (B) The relationship between the estimated $b_{\mathrm{bp}}(660)$ and the measured suspended particulate matter (SPM).

\subsection{Model Validation by the In-Situ and Match-Up Measurements}

The validation dataset (having 70 samples) and the match-up points (having 60 samples) were used to validate the semi-analytical algorithm of $K_{d}(490)$. The RMSP and MAPE of validation results between the measured and the derived $K_{d}(490)$ were $27.44 \%$ and $22.60 \pm 15.57 \%$, respectively (see Figure 5A). GOCI-derived $K_{\mathrm{d}}(490)$ was selected from satellite images according to the latitude and longitude of the match-up points. The RMSP and MAPE of the match-up points between the measured and the derived $K_{\mathrm{d}}(490)$ were respectively $34.29 \%$ and $27.57 \pm 20.56 \%$ (see Figure $5 \mathrm{~B}$ ). The validation results indicated that the performance of the semi-analytical $K_{\mathrm{d}}(490)$ algorithm is acceptable which can be used to estimate $K_{d}(490)$ from GOCI satellite images. 

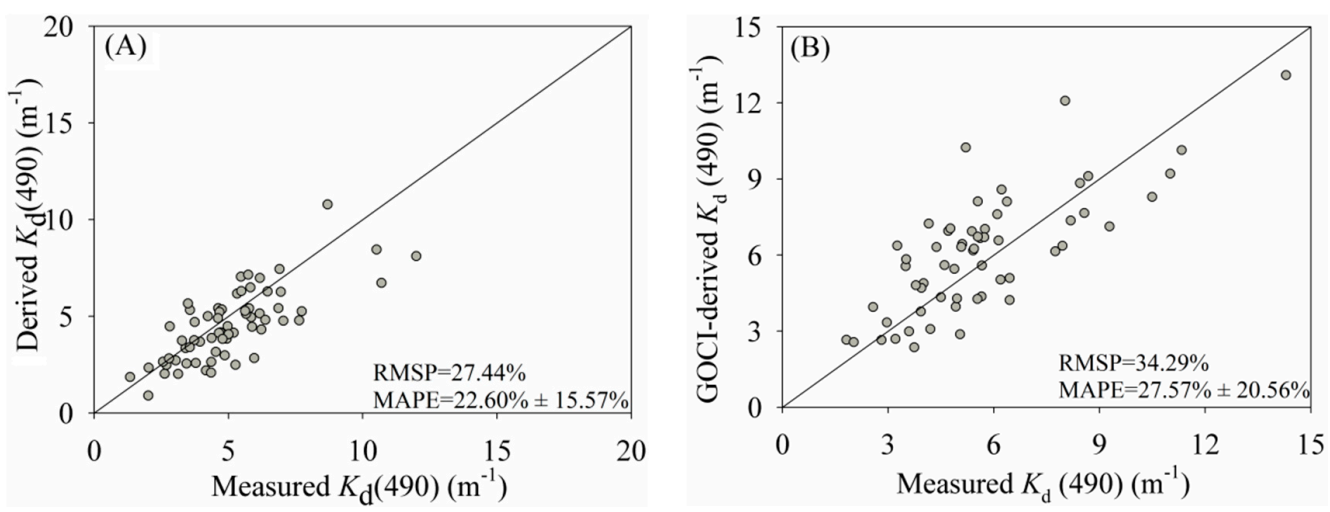

Figure 5. Comparison of the in-situ measured $K_{d}(490)$ and the estimated $K_{d}(490)$ for (A) validation dataset (with 70 samples) and (B) the match-up points (with 60 samples).

\subsection{Comparison with the Exist $K_{d}(490)$ Model for GOCI}

The previous studies proposed several semi-analytical algorithms for estimating $K_{d}(490)$ in the turbid water $[9,11,15]$. These semi-analytical algorithms were selected to compare the models (see Figure 6 and Table 1 ). The calibration dataset (282 points) was used to recalibrate the model parameters for Models 1, 2 and 3. Model 4 is an optimization algorithm which doesn't need calibration dataset. Thus, the validation results for Models 1, 2, 3 and 4 are getting from 70 points (validation dataset) and 372 points (validation and calibration dataset). Models 2 and 3 work well for the relatively low $K_{d}(490)$, but are slightly weak for the high $K_{d}(490)$. The performance of Model 4 in the high $K_{d}(490)$ is much better than Models 2 and 3, which is consistent with the previous studies in the turbid coastal water $[9,11,15]$. However, Model 4 will significantly overestimate $K_{d}(490)$ in the algal dominant water (see the red hollow circle in Figure 6), which indicates that, although the semi-analytical algorithm can be used to estimate $K_{\mathrm{d}}(490)$ in the high turbid eutrophication water, but its performance is affected by the local parameters and parameterization of the inherent optical properties.
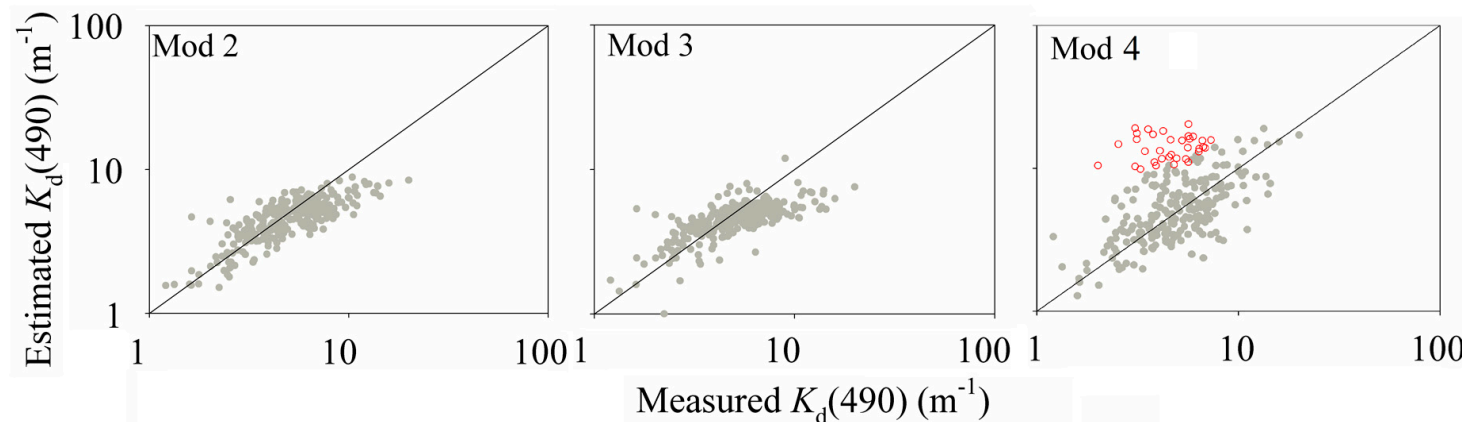

Figure 6. Comparison of the in situ measured $K_{\mathrm{d}}(490)$ and the estimated $K_{\mathrm{d}}(490)$ of Models 2,3 and 4 in the model set (see Table 1), Models 2 and 3 are from Huang [27].

Table 1. Comparison of the semi-analytical model sets for $K_{\mathrm{d}}(490)$. The validation results for Models 1, 2 and 3 are from validation dataset (having 70 points). Models 2 and 3 are from Huang [27]. The validation result for Model 4 is from 372 points (validation and calibration dataset) as it doesn't need calibration dataset.

\begin{tabular}{cccccc}
\hline Models & Variables & $\boldsymbol{R}^{\mathbf{2}}$ & RMSP & $\mid \mathbf{R E}$ I $_{\text {Max }}$ & MAPE \\
\hline Model 1 (This study) & $R_{\mathrm{rs}}(660) / R_{\mathrm{rs}}(555)$ & 0.57 & $27.44 \%$ & $76.11 \%$ & $22.60 \pm 15.57 \%$ \\
Model 2 [15] & $R_{\mathrm{rs}}(667), R_{\mathrm{rs}}(490)$ & 0.55 & $29.07 \%$ & $115.38 \%$ & $24.59 \pm 16.03 \%$ \\
Model 3 [9] & $R_{\mathrm{rs}}(488), R_{\mathrm{rs}}(645) / R_{\mathrm{rs}}(488)$ & 0.41 & $29.60 \%$ & $140.09 \%$ & $24.28 \pm 18.54 \%$ \\
Model 4 [11] & $(400-800 \mathrm{~nm}$ with 10 nm interval) & 0.44 & $33.23 \%$ & $175.27 \%$ & $31.24 \pm 24.16 \%$ \\
\hline
\end{tabular}




\section{Results and Discussion}

\subsection{Short-Term Observation of $K_{d}(490)$ from GOCI}

The hourly scale maps of GOCI-derived $K_{\mathrm{d}}(490)$ in Lake Taihu were obtained by using the semi-analytical algorithm (see Figure 7). The retrieval results of $K_{d}(490)$ in East Lake and East Bay (see the aquatic plant in Figure 1) were invalidated due to the effect of the submerged plants and bottom reflectance [28] and thus weren't shown in the retrieval results. The hourly scale maps of $K_{d}(490)$ can show the consecutive dynamic characteristics of $K_{\mathrm{d}}(490)$ at both the spatial and the temporal scales. The high $K_{d}(490)$ values were mainly distributed in the northwestern and southwestern areas of Lake Taihu as affected by sediment resuspension and algal blooms in summer [22,29]. The low $K_{d}(490)$ values were distributed beyond the algal bloom area, such as the center area of the lake, where sediment resuspension is rare (8 June 2013 in Figure 7). The dynamic characteristics of $K_{\mathrm{d}}(490)$ are consistent with the diffusion and migration of algae where sediment resuspension is weak (8 June 2013 in Figure 6). Sediment resuspension significantly regulates the distribution of $K_{d}(490)$ in Lake Taihu as a result of the high $K_{\mathrm{d}}(490)$ values coupled with the high wind speed, as observed on 8 August 2013 (see Figure 7). The high $K_{\mathrm{d}}(490)$ value of $8.67 \mathrm{~m}^{-1}$ appears when wind has reached $5.26 \pm 1.88 \mathrm{~m} \mathrm{~s}^{-1}$ for a duration of four hours. In conclusion, both algae and sediment resuspension can impact the distribution of $K_{\mathrm{d}}(490)$ in summer, and the algae or sediment resuspension is affected by wind speed. Thus, to derive the highly dynamic characteristics of $K_{\mathrm{d}}(490)$ requires the high temporal-resolution satellite data.

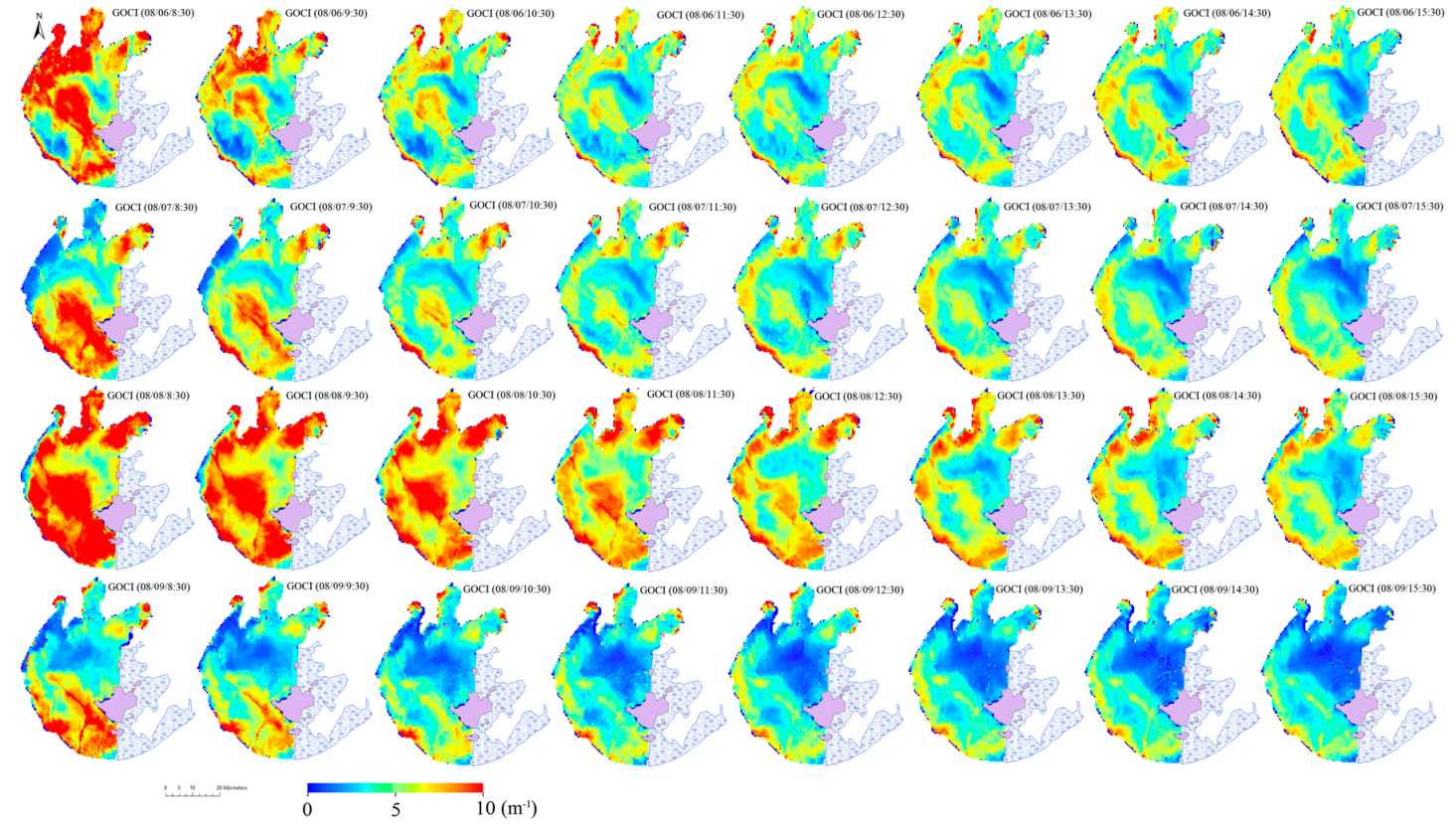

Figure 7. The spatial variations of $K_{\mathrm{d}}(490)$ mapped by GOCI data during daytime hours from August 6 to August 9. The retrieval results of $K_{\mathrm{d}}(490)$ in East Lake and East Bay (see the aquatic plant in Figure 1) are not shown.

\subsection{Comparison of MODIS-Derived and GOCI-Derived $K_{d}(490)$}

The transit time of MODIS satellite is similar to that of GOCI satellite; both of which pass over the territory at 13:30 (the local time). The comparison of the results retrievad from GOCI and MODIS satllite images shows that there were some inconsistencies between GOCI- and MODIS-derived $K_{d}(490)$ (marked by ellipses in Figure 8). The largest inconsistence was found in the central area of Lake Taihu, which has more than 100\% difference between GOCI- and MODIS-derived $K_{\mathrm{d}}(490)$ (8 June 2013 in Figure 8). Some relatively high inconsistencies were also found in the central area of the lake on 8 August 2013. The aforesaid inconsistences may be caused by the quick sediment resuspension in 
the central area of the lake according to the high dynamic characteristics (see the high wind speed at sites 3, 4 and 5 in Figure 1). However, the general patterns of $K_{\mathrm{d}}(490)$ distribution are consistent with each other, which indicates that models and satellite images are suitable for $K_{\mathrm{d}}(490)$ estimation from MODIS and GOCI. The mean differences $\left.\left(\left(K_{d}(490)\right)_{-M O D I S}-K_{d}(490){ }_{-G O C I}\right) / K_{d}(490){ }_{-G O C I}\right)$ between GOCI- and MODIS-derived $K_{\mathrm{d}}(490)$ in 8 June 2013, 8 July 2013, 8 August 2013 and 8 September 2013 are respectively $28.56 \pm 30.40 \%$ (the mean value \pm standard deviation), $-6.3 \pm 23.59 \%, 7.24 \pm 60.21 \%$ and $-4.04 \pm 20.47 \%$. The mean absolute differences (abs $\left(\left(K_{\mathrm{d}}(490){ }_{\text {-MODIS }}-K_{\mathrm{d}}(490){ }_{-\mathrm{GOCI}}\right) / K_{\mathrm{d}}(490){ }_{\text {GOCI }}\right)$ ) are respectively $30.80 \pm 28.20 \%, 11.73 \pm 21.42 \%, 15.72 \pm 59.62 \%$ and $13.53 \pm 15.88 \%$.
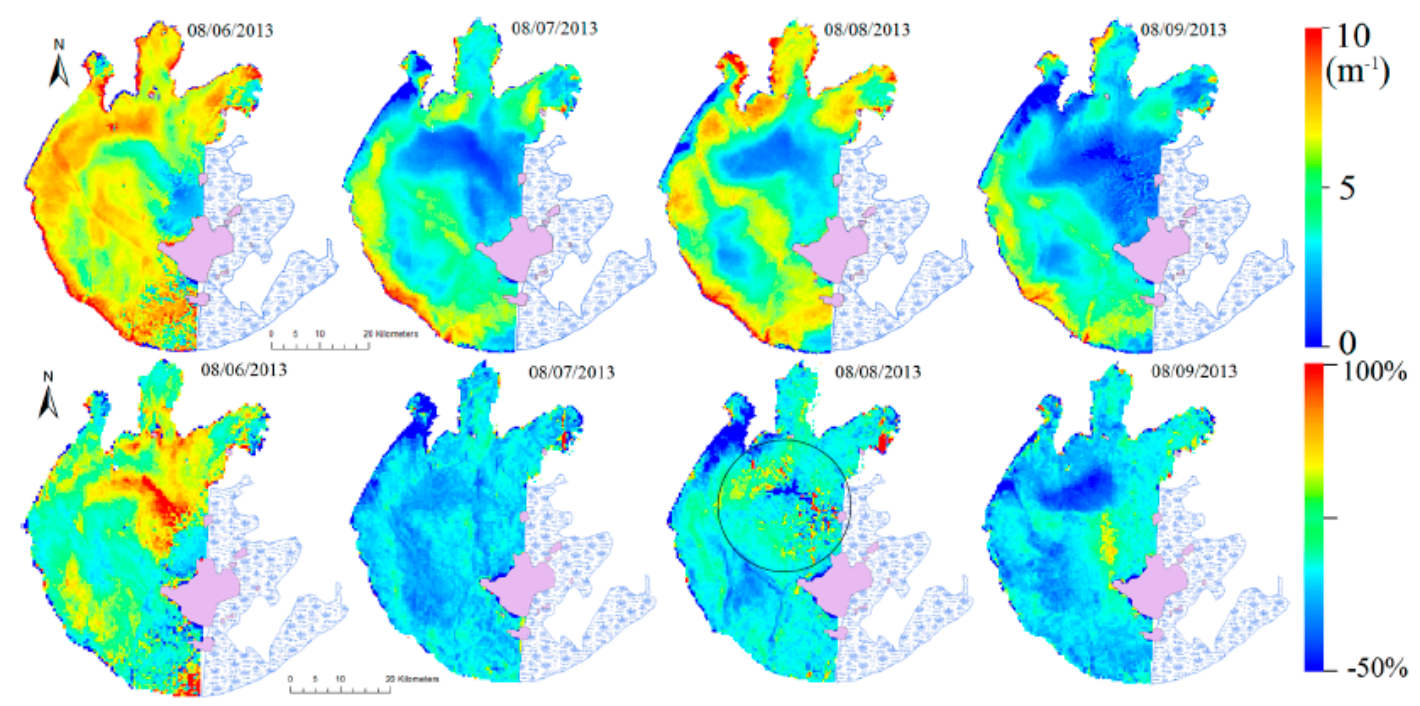

Figure 8. The above figures are the spatial variations of $K_{d}(490)$ mapped by MODIS data from August 6 to August 9. The figures below are the spatial differences (\%) between GOCI- and MODIS-derived $K_{\mathrm{d}}(490)$.

The MODIS-derived $K_{\mathrm{d}}(490)$ was re-sampled to the spatial resolution of $500 \mathrm{~m}$, which is same as that of GOCI. To further evaluate the consistency between GOCI- and MODIS-derived $K_{\mathrm{d}}(490)$ pixel by pixel, a scatterplot of the estimated $K_{\mathrm{d}}(490)$ from GOCI and MODIS data is shown in Figure 9. MODIS-derived $K_{\mathrm{d}}(490)$ was slightly higher than GOCI-derived $K_{\mathrm{d}}(490)$ on 8 June 2013, especially in the low value range (see Figure 9). It is clear that most of the pixels of $K_{d}(490)$ are consistently between the results from MODIS and GOCI (see 8 July 2013, 8 August 2013 and 8 September 2013 in Figure 9). The mean values of the linear-determined coefficient and RMSE of GOCI- and MODIS-derived $K_{\mathrm{d}}(490)$ are $0.44 \pm 0.13$ and $1.51 \pm 0.31 \mathrm{~m}^{-1}$, respectively. Given the discrepancies in the satellite image process and the $K_{\mathrm{d}}(490)$ algorithm and the signal/noise ratio from MODIS and GOCI, a comparison between MODIS- and GOCI-derived $K_{\mathrm{d}}(490)$ indicates that the combination of MODIS and GOCI satellite data can provide the long-term observation of $K_{\mathrm{d}}(490)$ with the detailed short-term dynamic information.

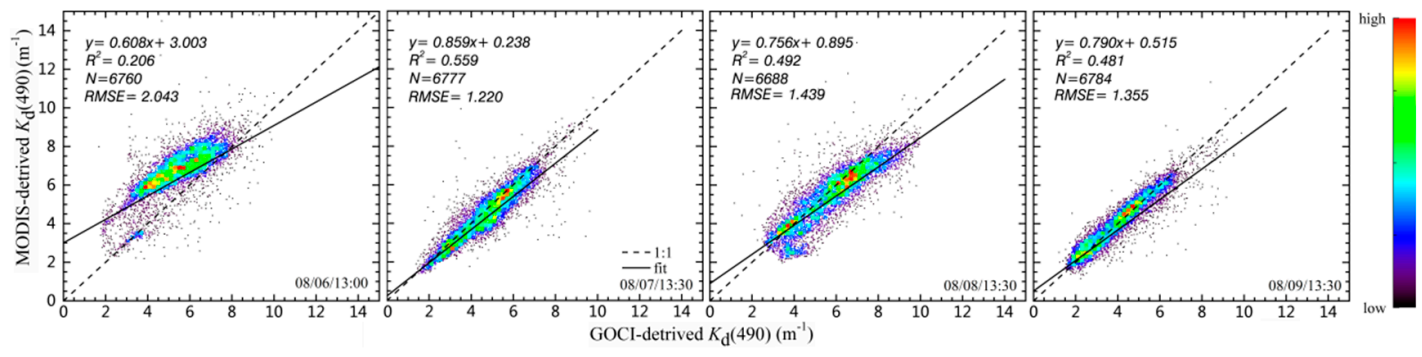

Figure 9. Comparison between GOCI- and MODIS-derived $K_{d}(490)$ for matching up satellite images pixel by pixel. The bad pixels were removed. 


\subsection{Wind-Driven Variation of $K_{d}(490)$ from GOCI-Derived $K_{d}(490)$}

The strength and duration of wind govern the sediment resuspension and the formation of algal blooms [29-32]. Floating algae will appear on the water surface when the wind speed is low, which would suspend on the water if the wind speed increases [23,33-35]. $K_{\mathrm{d}}(490)$ will significantly increase as a result of sediment resuspension caused by wind speed increase [36]. Consequently, wind drives the variation of $K_{\mathrm{d}}(490)$ by distributing algae and causing sediment resuspension. However, wind's regulating effect on $K_{\mathrm{d}}(490)$ also varies with spaces due to the impact of the lacustrine morphology and fetch length. The hourly values of wind speed and $K_{d}(490)$ are presented in Figure 10 (the sites correspond with the buoy sample sites in Figure 1). Variations of wind speed and $K_{\mathrm{d}}(490)$ in sites 1 and 6 are clearly different from the others as $K_{\mathrm{d}}(490)$ increases with a wind speed decrease (see the black box in sites 1 and 6 of Figure 10) due to floating algae in sites 1 and 6 (algae dominant) [23]. $K_{d}(490)$ also decreases with a reduction in wind speed (see the green boxes in sites 1 and 6 of Figure 10) when wind speed is higher than $5 \mathrm{~m} \mathrm{~s}^{-1}$. Due to the persistent high wind speed before this period, the floating algae replaced the sediment resuspension. $K_{\mathrm{d}}(490)$ was highly and positively related to wind speed in sites 3,4 and 5 ( $r=0.5,0.7$ and 0.8 respectively), which was caused by sediment resuspension from 8 June to 8 September (sediment resuspension dominant type and floating algae are very rare). The relationships between wind speed and $K_{d}(490)$ in sites 2 and 7 were not validated, which may be caused by the unstable wind directions in these two points due to the impact of land. Thus, wind drove the variation of $K_{\mathrm{d}}(490)$ but were affected by the lacustrine morphology and wind directions.

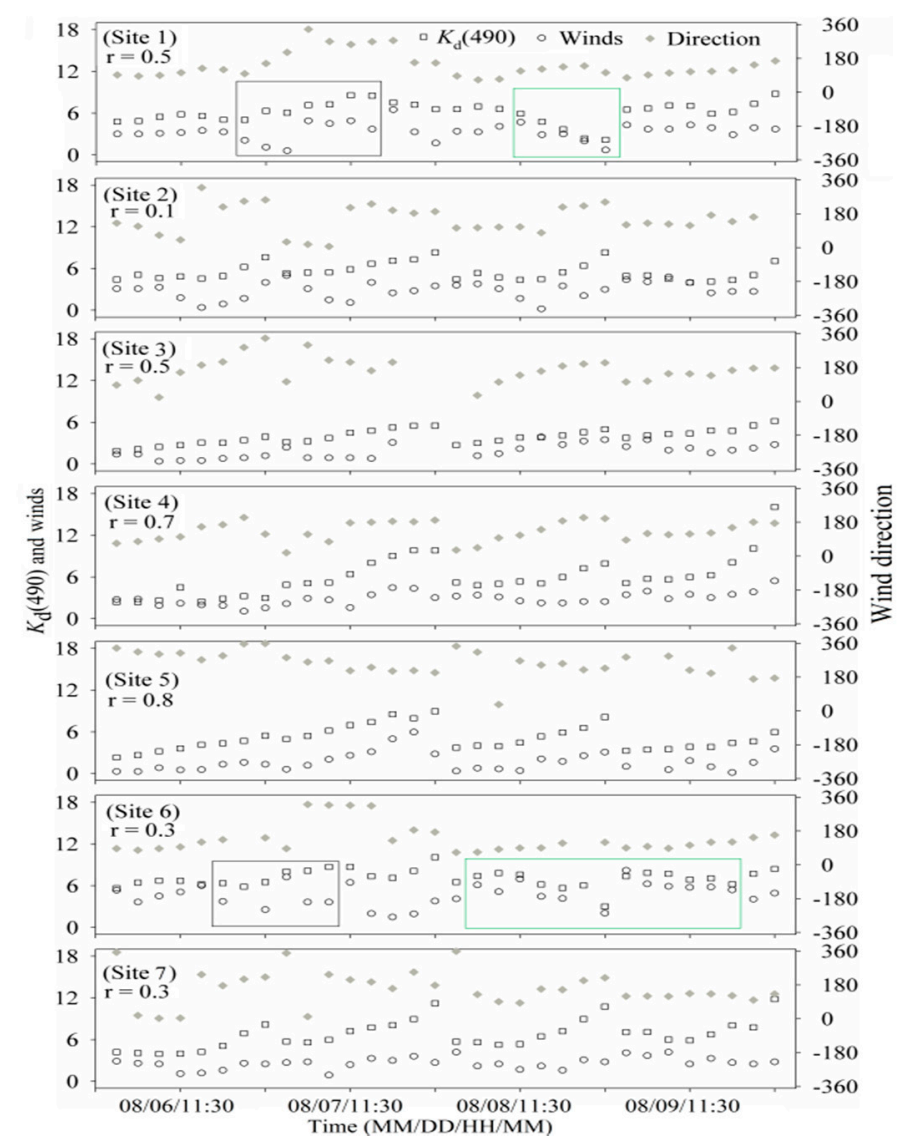

Figure 10. The hourly variation of GOCI-derived $K_{d}(490)$ with wind speeds and directions for different buoy monitor sites.

To further reveal the relationship between wind speed and $K_{\mathrm{d}}(490), K_{\mathrm{d}}(490)$ was divided into three types according to the strength of wind $\left(0-3 \mathrm{~m} \mathrm{~s}^{-1}, 3-4 \mathrm{~m} \mathrm{~s}^{-1}\right.$ and $\left.>4 \mathrm{~m} \mathrm{~s}^{-1}\right)$, corresponding to 
the critical wind speeds of algal blooms and sediment resuspension $[23,33]$. When the wind speed was less than $3 \mathrm{~m} \mathrm{~s}^{-1}, K_{\mathrm{d}}(490)$ varied from $1.87 \mathrm{~m}^{-1}$ to $11.22 \mathrm{~m}^{-1}$ with a mean value of $4.92 \pm 1.71 \mathrm{~m}^{-1}$. Such wind speed can explain $19.14 \%$ of the variation of $K_{\mathrm{d}}(490)$ due to the dominant effect of algal blooms (linear $R^{2}=0.19, p<0.0001$ ). When the wind speed was less than $3 \mathrm{~m} \mathrm{~s}^{-1}, K_{\mathrm{d}}(490)$ ranged from 3.84 to $10.78 \mathrm{~m}^{-1}$ with a mean value of $6.47 \pm 1.67 \mathrm{~m}^{-1}$, and the relationship between the wind speed and $K_{\mathrm{d}}(490)$ was relatively weak (linear $\left.R^{2}=0.02, p<0.28\right)$. When the wind speed was less than $3 \mathrm{~m}$ $\mathrm{s}^{-1}, K_{\mathrm{d}}(490)$ ranged from 4.51 to $10.37 \mathrm{~m}^{-1}$ with a mean value of $6.95 \pm 1.22 \mathrm{~m}^{-1}$. Such wind speed can explain $35.57 \%$ of the variation of $K_{d}(490)$ due to sediment resuspension, and the ratio of which would increase to $59.58 \%$ when the black point in Figure 11 has been removed. The regression formula for wind speed $(W)$ and $K_{\mathrm{d}}(490)$ at the lowest value of each wind speed range (see the floor level of Figure 11) is $K_{\mathrm{d}}(490)=2.293+0.466^{*}\left(\exp \left(0.160^{*} W\right)-1\right) / 0.160\left(R^{2}=0.89, p<0.0001, \mathrm{~N}=64\right)$, which may be caused by the relationship between wind speed $(W)$ and $K_{\mathrm{d}}(490)$ due to sediment resuspension.

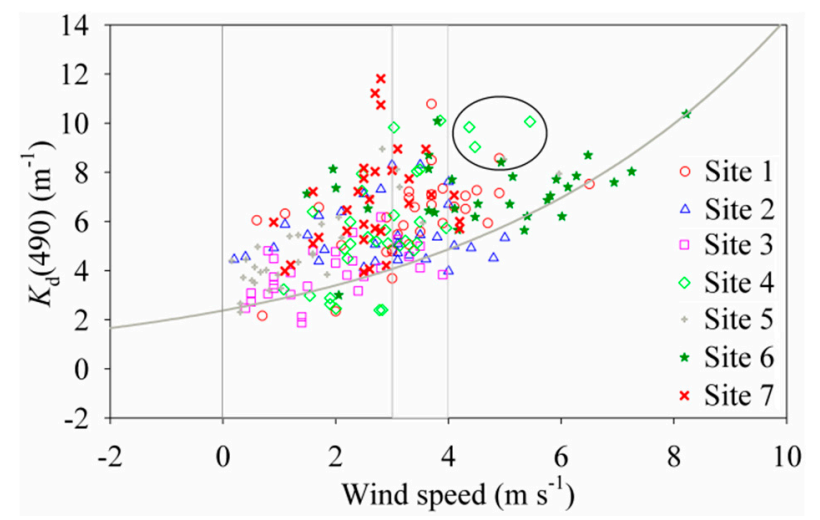

Figure 11. Scatterplot comparing wind speed and $K_{d}(490)$ in different sites. The regression line is at the floor level of $K_{\mathrm{d}}(490)$ for different wind speeds.

\section{Conclusions}

The knowledge in respect of the short-term variation of the diffuse attenuation coefficient can help reveal its driving factors at the short time scales, such as wind speed. A semi-analytical algorithm of $K_{\mathrm{d}}(490)$, which inserts an empirical model between the band-ratio $\left(R_{\mathrm{rs}}(660) / R_{\mathrm{rs}}(555)\right)$ and $b_{\mathrm{bp}}(660)$, was developed based on the in-situ measurement of $R_{\mathrm{rs}}$ and $K_{\mathrm{d}}(490)$ for the high temporal-resolution of the GOCI satellite. The performance of the aforesaid semi-analytical algorithm for validation dataset shows that the RMSP and MAPE between the measured and the derived $K_{\mathrm{d}}(490)$ are respectively $27.44 \%$ and $22.60 \pm 15.57 \%$. The RMSP and MAPE between the measured and the derived $K_{\mathrm{d}}(490)$ are respectively $34.29 \%$ and $27.57 \pm 20.56 \%$, which indicated the feasibility of applying such algorithm in GOCI satellite images. The high temporal-resolution satellite data for monitoring the dynamic characteristics of $K_{\mathrm{d}}(490)$ is necessary in the high dynamic-ratio lake. The comparison between GOCIand MODIS-derived $K_{\mathrm{d}}(490)$ manifested that GOCI-derived $K_{\mathrm{d}}(490)$ can capture the spatial variation and the dynamic characteristics of $K_{\mathrm{d}}(490)$ in a good manner. It's been found that wind is a primary driving factor in the spatial and temporal variation of $K_{\mathrm{d}}(490)$, though its driving effect on $K_{\mathrm{d}}(490)$ varied with the lacustrine morphometry (such as the effect in the center area of the lake is different from that in bays and the lake shore).

Acknowledgments: This study was supported by the National Natural Science Foundation of China (Grant Nos. 41571324, 41503075, and 41673108) and funded by the Priority Academic Program Development of Jiangsu Higher Education Institutions, the State Key Laboratory of Lake Science and Environment (2016SKL005), GDAS' Special Project of Science and Technology Development (2017GDASCX-0801) and the Jiangsu Planned Projects for Postdoctoral Research Funds.

Author Contributions: Ling Yao principally conceived the idea for the study and was responsible for the design of the study, Changchun Huang was responsible for setting up experiments, completing the experiments and 
retrieving data and he also wrote the initial draft of the manuscript. Ling Yao revised the paper. Both authors participated in some form in the concept, experimentation, writing and/or editing of this manuscript.

Conflicts of Interest: The authors declare no conflict of interest. The founding sponsors had no role in the design of the study; in the collection, analyses, or interpretation of data; in the writing of the manuscript, and in the decision to publish the results.

\section{References}

1. Kirk, J.T.O. Dependence of relationship between inherent and apparent optical properties of water on solar altitude. Limnol. Oceanogr. 1984, 29, 350-356. [CrossRef]

2. Preisendorfer, R.W. Hydrologic Optics, vol. 1. Introduction. Available online: http://udspace.udel.edu/ handle/19716/1577 (accessed on 20 May 2017).

3. Lee, Z.P.; Darecki, M.; Carder, K.L.; Davis, C.; Stramski, D.; Rhea, W.J. Diffuse attenuation coefficient of downwelling irradiance: Anevaluation of remote sensing methods. J. Geophys. Res. 2005, 110. [CrossRef]

4. Lee, Z.; Hu, C.M.; Shang, S.; Du, K.; Lewis, M.; Arnone, R.; Brewin, R. Penetration of UV-Visible solar light in the global oceans: Insights from ocean color remote sensing. J. Geophys. Res. 2013, 118, 4241-4255. [CrossRef]

5. Shi, K.; Zhang, Y.L.; Liu, X.H.; Wang, M.Z.; Qin, B.Q. Remote sensing of diffuse attenuation coefficient of photosynthetically active radiation in Lake Taihu using MERIS data. Remote Sens. Environ. 2014, 140, 365-377. [CrossRef]

6. Song, K.S.; Ma, J.H.; Wen, Z.D.; Fang, C.; Shang, Y.X.; Zhao, Y.; Wang, M.; Du, J. Remote estimation of Kd(PAR) using MODIS and Landsat imagery for turbid inland waters in northeast China. ISPRS J. Photogramm. Remote Sens. 2017, 123, 159-172. [CrossRef]

7. Zhang, Y.L.; Liu, X.H.; Yin, Y.; Wang, M.Z.; Qin, B.Q. A simple optical model to estimate diffuse attenuation coefficient of photosynthetically active radiation in an extremely turbid lake from surface reflectance. Opt. Express 2012, 20, 20482-20493. [CrossRef] [PubMed]

8. Read, J.S.; Rose, K.C.; Winslow, L.A.; Read, E.K. A method for estimating the diffuse attenuation coefficient (KdPAR) from paired temperature sensors. Limnol. Oceanogr. Methods 2015, 13, 53-61. [CrossRef]

9. Wang, M.H.; Son, S.H.; Lawrence, W.; Harding, J. Retrieval of diffuse attenuation coefficient in the Chesapeake Bay and turbid ocean regions for satellite ocean color applications. J. Geophys. Res. 2009, 114. [CrossRef]

10. Wang, M.H.; Ahn, J.H.; Jiang, L.; Shi, W.; Son, S.H.; Park, Y.J.; Ryu, J.H. Ocean color products from the Korean Geostationary Ocean Color Imager (GOCI). Opt. Express 2013, 21, 3835-3849. [CrossRef] [PubMed]

11. Yu, X.L.; Salama, M.S.; Shen, F.; Verhoef, W. Retrieval of the diffuse attenuation coefficient from GOCI images using the 2SeaColor model: A case study in the Yangtze Estuary. Remote Sens. Environ. 2016, 175, 109-119. [CrossRef]

12. Zhang, T.L.; Fell, F. An empirical algorithm for determining the diffuse attenuation coefficient $K_{d}$ in clear and turbid waters from spectral remote sensing reflectance. Limnol. Oceanogr. Methods 2007, 5, 457-462. [CrossRef]

13. Majozi, N.P.; Salama, M.S.; Bernard, S.; Harper, D.M.; Habte, M.G. Remote sensing of euphotic depth in shallow tropical inland waters of Lake Naivasha using MERIS data. Remote Sens. Environ. 2014, 148, 178-189. [CrossRef]

14. Zhang, G.; Stramski, D.; Reynolds, R.A. Evaluation of the QAA algorithm for estimating the inherent optical properties from remote sensing reflectance in Arctic waters. In Proceedings of the 2010 Ocean Sciences Meeting, Portland, OR, USA, 22-26 February 2010.

15. Chen, J.; Cui, T.W.; Tang, J.W.; Song, Q.J. Remote sensing of diffuse attenuation coefficient using MODIS imagery of turbid coastal waters: A case study in Bohai Sea. Remote Sens. Environ. 2014, 140, 78-93. [CrossRef]

16. Mueller, J.L. SeaWiFS algorithm for the diffuse attenuation coefficient, K(490), using water-leaving radiances at 490 and $555 \mathrm{~nm}$. SeaWiFS Postlaunch Calibration Valid. Anal. 2000, 3, 24-27.

17. Wang, M.H.; Shi, W.; Tang, J.W. Water property monitoring and assessment for China's inland Lake Taihu from MODIS-Aqua measurements. Remote Sens. Environ. 2011, 115, 841-854. [CrossRef] 
18. Saulquin, B.; Hamdi, A.; Gohin, F.; Populus, J.; Mangin, A.; d'Andona, O.F. Estimation of the diffuse attenuation coefficient $\mathrm{K}_{\mathrm{dPAR}}$ using MERIS and application to seabed habitat mapping. Remote Sens. Environ. 2015, 128, 224-233. [CrossRef]

19. Lee, Z.P.; Carder, K.L.; Robert, A.A. Deriving inherent optical properties from water color: A multiband quasi-analytical algorithm for optically deep waters. Appl. Opt. 2002, 41, 5755-5772. [CrossRef] [PubMed]

20. Doron, M.; Babin, M.; Mangin, A.; Hembise, O. Estimation of light penetration, and horizontal and vertical visibility in oceanic and coastal waters from surface reflectance. J. Geophys. Res. 2007, 112. [CrossRef]

21. Ma, R.H.; Pan, D.L.; Duan, H.T.; Song, Q.J. Absorption and scattering properties of water body in Taihu Lake, China: Backscattering. Int. J. Remote Sens. 2009, 30, 2321-2335. [CrossRef]

22. Huang, C.C.; Li, Y.M.; Yang, H.; Sun, D.Y.; Yu, Z.Y.; Zhang, Z.; Chen, X.; Xu, L.J. Detection of algal bloom and factors influencing its formation in Taihu Lake from 2000 to 2011 by MODIS. Environ. Earth Sci. 2014, 71, 3705-3714. [CrossRef]

23. Huang, C.C.; Shi, K.; Yang, H.; Li, Y.M.; Zhu, A.X.; Sun, D.Y.; Xu, L.J.; Zou, J.; Chen, X. Satellite observation of hourly dynamic characteristics of algae with Geostationary Ocean Color Imager (GOCI) data in Lake Taihu. Remote Sens. Environ. 2015, 159, 278-287. [CrossRef]

24. Guanter, L.; Ruiz-Verdú, A.; Odermatt, D.; Giardino, C.; Simis, S.; Estellés, V.; Heege, T.; Domínguez-Gómez, J.A.; Moreno, J. Atmospheric correction of ENVISAT/MERIS data over inland waters: Validation for European lakes. Remote Sens. Environ. 2010, 114, 467-480. [CrossRef]

25. Liu, G.; Li, Y.M.; Lv, H.; Wang, S.; Du, C.G.; Huang, C.C. An improved land target-based atmospheric correction method for Lake Taihu. IEEE Sel. Top. Appl. Earth Obs. Remote Sens. 2016, 9, 793-803. [CrossRef]

26. Budhiman, S.; Salama, M.S.; Vekerdy, Z.; Verhoef, W. Deriving optical properties of Mahakam Delta coastal waters, Indonesia using in situ measurements and ocean color model inversion. ISPRS J. Photogramm. Remote Sens. 2012, 68, 157-169. [CrossRef]

27. Huang, C.C.; Yao, L.; Huang, T.; Zhang, M.L.; Zhu, A.X.; Yang, H. Wind and rainfall regulation of the diffuse attenuation coefficient in large, shallow lakes from long-term MODIS observations using a semi-analytical model. J. Geophys. Res. Atmos. 2017, 122. [CrossRef]

28. Hu, C.M.; Lee, Z.P.; Ma, R.H.; Yu, K.; Li, D.Q.; Shang, S.L. Moderate Resolution Imaging Spectroradiometer (MODIS) observations of cyanobacteria blooms in Taihu Lake, China. J. Geophys. Res. Oceans 2010, 115, 216-263. [CrossRef]

29. Qin, B.; Hu, W.; Gao, G.; Luo, L.; Zhang, J. Dynamics of sediment resuspension and the conceptual schema of nutrient release in the large shallow Lake Taihu, China. Chin. Sci. Bull. 2004, 49, 54-64. [CrossRef]

30. Hawley, N. Response of the benthic nepheloid layer to near-inertial internal waves in southern Lake Michigan. J. Geophys. Res. 2004, 109, 249-260. [CrossRef]

31. Marti, C.L.; Imberger, J. Exchange between litto-ral and pelagic waters in a stratified lake due to wind-induced motions: Lake Kinneret, Israel. Hydrobiologia 2008, 603, 25-51. [CrossRef]

32. Valipour, R.; Boegman, L.; Bouffard, D.; Rao, Y.R. Sediment resuspension mechanisms and their contributions to high-turbidity events in a large lake. Limnol. Oceanogr. 2017, 62, 1045-1065. [CrossRef]

33. Cao, H.S.; Kong, F.X.; Luo, L.C.; Shi, X.L. Effects of wind and wind-induced waves on vertical phytoplankton distribution and surface blooms of Microcystis aeruginosa in Lake Taihu. J. Freshw. Ecol. 2016, 21, 231-238. [CrossRef]

34. Wynne, T.T.; Stumpf, R.P.; Tomlinson, M.C.; Dyble, J. Characterizing a cyanobacterial bloom in western Lake Erie using satellite imagery and meteorological data. Limnol. Oceanogr. 2010, 55, 2025-2036. [CrossRef]

35. Binding, C.E.; Greenberg, T.A.; Bukata, R.P. Time series analysis of algal blooms in Lake of the Woods using the MERIS maximum chlorophyll index. J. Plankton Res. 2011, 33, 1847-1852. [CrossRef]

36. Huang, C.C.; Yang, H.; Zhu, A.X.; Zhang, M.L.; Lü, H.; Huang, T.; Zou, J.; Li, Y.M. Evaluation of the Geostationary Ocean Color Imager (GOCI) to monitor the dynamic characteristics of suspension sediment in Taihu Lake. Int. J. Remote Sens. 2015, 36, 3859-3874. [CrossRef]

(C) 2017 by the authors. Licensee MDPI, Basel, Switzerland. This article is an open access article distributed under the terms and conditions of the Creative Commons Attribution (CC BY) license (http://creativecommons.org/licenses/by/4.0/). 